Institutional Report

\title{
Recent Advances in the Indian Tsunami Early Warning System
}

SUNANDA MANNEELA, E UMA DEVI, DIPANKAR SAIKIA, T SRINIVASA KUMAR and S S C SHENOI*

ESSO-Indian National Centre for Ocean Information Services (INCOIS), Hyderabad, India

(Received on 10 May 2016; Accepted on 25 June 2016)

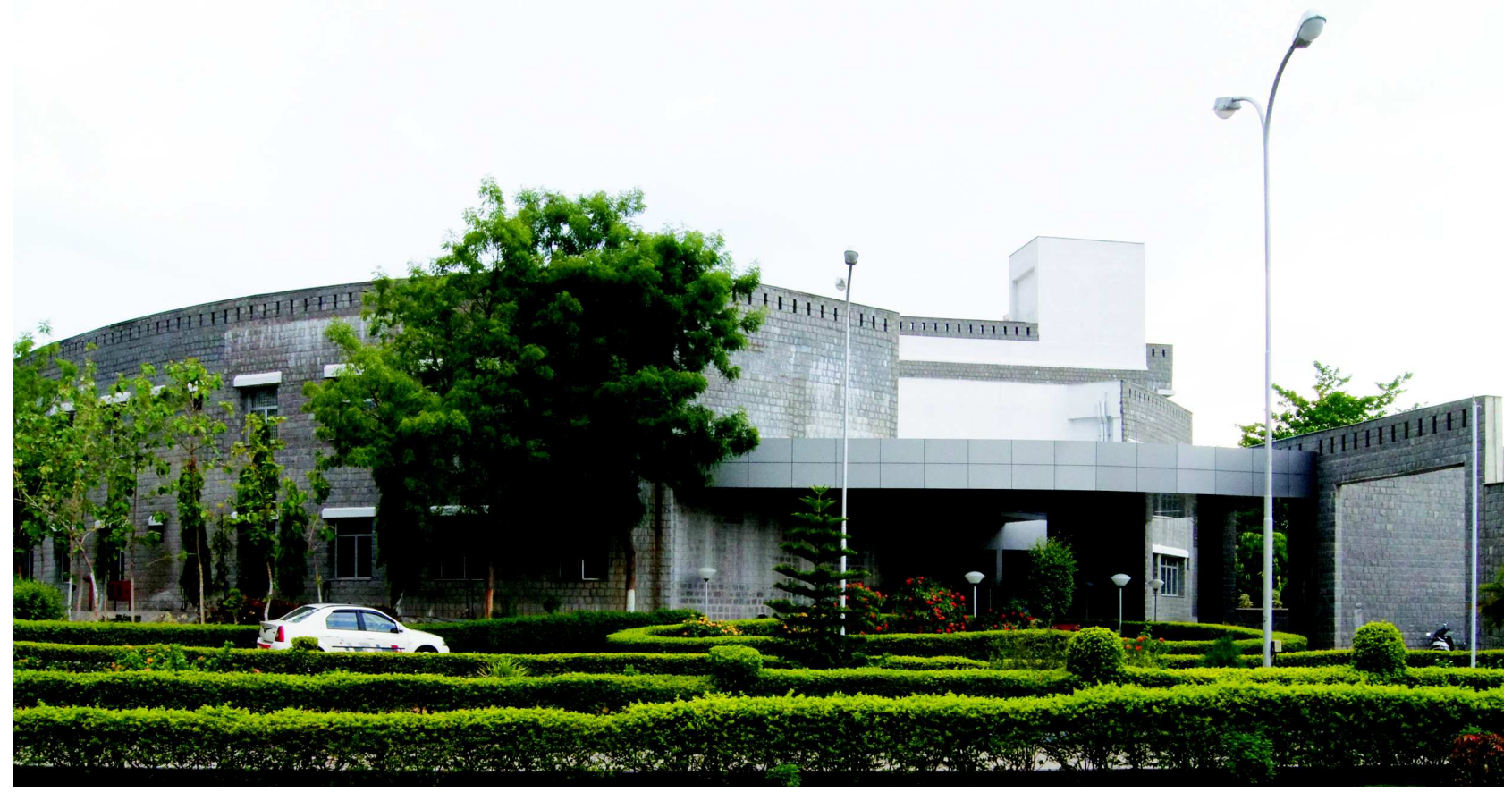

\section{Introduction}

The Sumatra earthquake of December 26, 2004 generated a tsunami that affected most of the Indian Ocean rim countries. The tsunami caused catastrophic losses of life and property in near field and the far field regions, such as Somalia. Although people living at the coast near the epicenter of the earthquake had little time to escape, those living farther along the coasts of Sri Lanka, India, Maldives and the countries on the east coast of Africa had time to move to the higher grounds to protect themselves. Unfortunately, the loss was inevitable as there was no tsunami warning system in place in the Indian Ocean. The overall loss made this event a prime educator for the people around the world about the hazardous tsunami and highlighted a global failure in mitigating such disaster.

The recent tsunamis in Samoa (2009), Chile (2010) and Japan (2011) reminded the world that, though rare, these events could be more disastrous in comparison to floods, cyclones, etc. Recent experiences suggest that with appropriate scientific

\footnotetext{
*Authorfor Correspondence: E-mail: shenoi@incois.gov.in
} 
inputs policy makers/administrators can take actions to save lives, reduce the losses and speed up the response procedures. Thus in the wake of 2004 tsunami, Government of India established the Indian Tsunami Early Warning System (ITEWS) at Earth System Science Organization-Indian National Centre for Ocean Information Services (INCOIS), Hyderabad, as an autonomous institution of Ministry of Earth Sciences (MoES).

The Indian Tsunami Early Warning Centre (ITEWC) continuously monitors the seismic waves recorded by a network of seismic stations (Fig. 1) well spread across the globe to determine the magnitudes, depths and locations of earthquake's. Then it combines the parameters with pre-computed hazard estimates based on tsunami models based on from similar events to decide, the potential of the earthquake for generating a tsunami, and if so, then it estimates the anticipated height of the tsunami wave at different locations on the coast.

Data from the global seismic stations available on the Incorporated Research Institutions for Seismology (IRIS), Global Seismographic Network (GSN), GEOFON (GEOFOrschungsNetz) networks (approx. 350 Nos) and the national seismic stations (17 Nos) are utilized to detect the earthquakes. Recently extended seismic network, established as the Indian Seismic and GNSS Network (ISGN) will now provide data from additional 100 seismic stations. Data from additional seismograms have further reduced the time required for the detection of earthquake and on the accuracy of source parameters estimation.

Currently, ESSO-INCOIS is developing and testing an algorithm for near real-time source

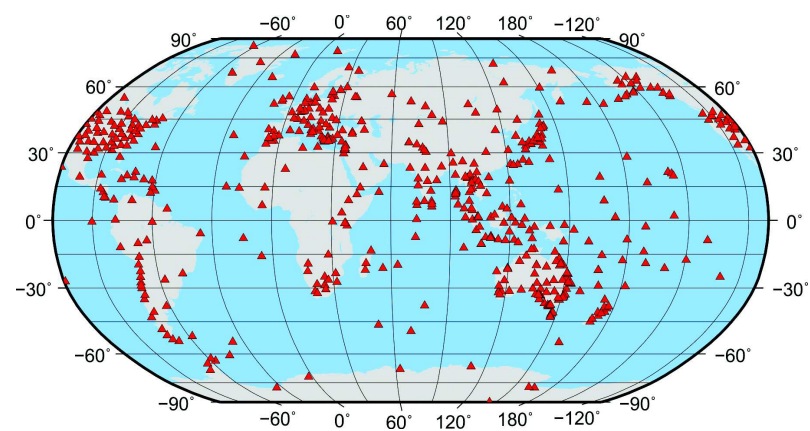

Fig. 1: The location of seismic stations networked at ITEWC for the detection of earthquakes parameter estimations using strong motion accelerometers and GNSS receivers. For this purpose, INCOIS is establishing a network of 35 strong motion sensors and GNSS in Andaman and Nicobar Islands with real time data connectivity through the ISGN network. A new decision support tool built on spatial data will help in limiting the geographical extent of advisories only to the regions with perceived threat. With these advancements, ,during October 2012, IOC/ UNESCO recognized ITEWC as a Tsunami Service Provider (TSP) for the entire Indian Ocean region making ITEWC, serving as a technical service provider for 28 Indian Ocean rim countries.

Following the establishment of tsunami early warning system, the studies on tsunamis and tsunami deposits also have rapidly expanded in India and elsewhere in the Indian Ocean region. This report briefs on the ITEWS components, its enhancements and the studies carried out on paleo-tsunamis in India during the past four years.

\section{Indian Tsunami Early Warning System (ITEWS)}

The ITEWS is a unified system made up for hazard identification and risk assessment, detection and dissemination. Capacity building through community awareness and preparedness is another activity of ITEWS. The ITEWC uses data from national and international observational network of seismic stations, sea level gauge stations and tsunami buoys around the Indian and Pacific Oceans. Data from approximately 400 seismometers (Fig. 1) is received in real-time and processed automatically to detect an earthquake of magnitude 4.0 and above anywhere on the globe. As soon as the earthquake is detected, warning centre transmits the first bulletin based on seismic data describing the location of earthquake, its magnitude, depth and other characters of the event. After the first bulletin, seismic data are further analysed for improved accuracy of earthquake parameters (magnitude, depth and location). The processing of seismic data is optimized to detect and characterize large earthquakes within earliest possible time.

The Indian Tsunami Early Warning Centre (ITEWC) acts as an operational centre and functions on $24 \times 7$ basis. For an earthquake in the Indian Ocean region, the ITEWC analyses its potential for generating a tsunami and issues advisories based on 
pre-computed simulations. The warning centre maintains a large database of pre-run scenarios created for the unit sources covering all the tsunamigenic sources in the Indian Ocean region using TUNAMI N2 model (Kuwayama, 2006) customized for the Indian Ocean region (Kumar et al., 2012). An exclusive decision support system automatically selects the basic unit source and computes the open ocean propagation scenario from the pre-computed simulations. This is based on the location and magnitude of the earthquake and scales (up/down) the source parameters using scaling relations to represent realistic situation (Papazachos et al., 2004). This enables an assessment of the possibility of tsunami generation, and the likely severity due to the arrival of tsunami waves at various locations along the coasts of India. It then generates appropriate advisories for disaster management agencies.

Concurrent with the seismic data analysis, the sea level data (tsunami buoys $\&$ tide/sea level gauges) are monitored to know whether the tsunami has actually occurred due to an earthquake and what could be the actual magnitude of the tsunami wave. ESSOINCOIS network comprises of seven tsunami buoys in the Indian Ocean supplemented by twenty one tide gauge stations all along the coasts (Kumar et al., 2015). Currently, four new tsunami buoys and ten additional tide gauge stations are also deployed in the Indian Ocean and on the Indian coast to further strengthen the observation network. Depending on the location of earthquake, such as in the case of December 2004 earthquake, the tsunami waves can reach the Indian coast in $\sim 20$ minutes (Andaman \& Nicobar Islands) to $\sim 3$ hours (east coast of Indian mainland).

Based on the severity of tsunami evaluations, timely tsunami advisories (Warning/Alert/Watch) are disseminated to national emergency points of contact to initiate necessary action. Advisories are updated at least hourly or as the conditions warrant till the all clear bulletin is issued.

\section{International Activities}

The severity of the 2004 Indian Ocean tsunami suggested that the devastation was due to the absence of tsunami warning system in the Indian Ocean. At the general assembly of Intergovernmental Oceanographic Commission (IOC) in 2005, it was proposed to establish ICGs (Intergovernmental Coordination Groups) for the IOTWMS (Indian Ocean Tsunami Warning and Mitigation System). India was elected to Chair the ICG/ITOWMS. Accordingly, under the supervision of ICG/IOTWMS it was decided to have a system of systems, to detect and issue the tsunami early warnings for the Indian Ocean. The system of systems approach took advantage of the observing systems established by several countries in the aftermath of the 2004 event. Later in October, 2012, the ITEWC was recognized as Tsunami Service Provider (TSP) for the Indian Ocean region. The area of responsibility for the ICG/IOTWMS in shown in Fig. 3. As part of the regional operations, the ITEWC actively participates in bi-annual Communication Tests (COMMs Tests), Standard Operating Procedures workshops, Tabletop exercises and Mock Tsunami Drills (Indian Ocean Wave Exercises). These are conducted by ICG/IOTWMS. These tests validate the timely dissemination and reception of tsunami notification messages by the Indian Ocean rim countries through various modes of communication like, SMS, GTS, FAX, email and web access.. The website provides the bulletins containing threat maps and tsunami information tables with time of wave

Table 1: ITEWC performance indicators for the period 2012-2016

\begin{tabular}{llcc}
\hline Parameter & Target & \multicolumn{2}{c}{$\begin{array}{c}\text { Achievement } \\
\text { Indian Ocean } \\
\text { Global Ocean } \\
(160)\end{array}$} \\
\hline Elapse time from earthquake origin time to initial earthquake information issuance & $10 / 15 \mathrm{~min}$ & $8.67 \mathrm{~min}$ & $10.77 \mathrm{~min}$ \\
Probability of detection of Indian Ocean earthquakes with Mw e" 6.5 & $100 \%$ & $100 \%$ & $100 \%$ \\
Accuracy of hypocenter location (with respect to USGS final estimates) & Within 30 km & $20.93 \mathrm{~km}$ & $15.36 \mathrm{~km}$ \\
Accuracy of hypocenter depth (with respect to USGS final estimates) & Within $25 \mathrm{~km}$ & $21.93 \mathrm{~km}$ & $24.29 \mathrm{~km}$ \\
Accuracy of earthquake $M w$ magnitude (with respect to USGS final estimates) & 0.3 & 0.25 & 0.23 \\
\hline
\end{tabular}



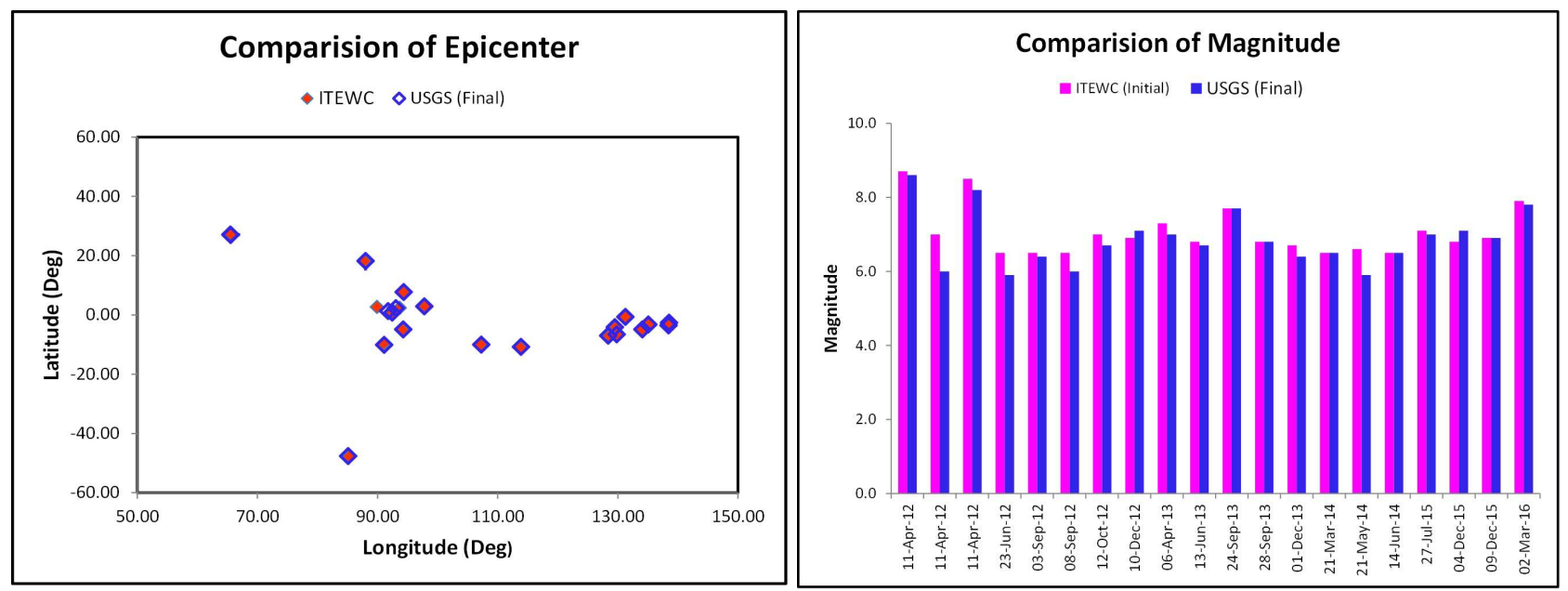

Fig. 2: Performance of ITEWC (initial estimates) compared with USGS (final estimates) of earthquake parameters

arrival and wave amplitude at each location. Later bulletins also include the water level changes as recorded by the sea level gauges and tsunami buoys.

During the period (April, 2012 till March 31, 2016 ITEWC has monitored 181 earthquakes of magnitude $\geq 6.5$ in the Indian Ocean as well as in Pacific and Atlantic Oceans. A summary of the performance of the warning centre against the key indicators (prescribed by IOC-ICG/IOTWMS-V/13) for the above events is given in Table 1 . Graphical representation of ITEWC performance compared with USGS is given in Fig. 2.

\section{Indian Seismic \& GNSS Network}

Early detection and characterization of earthquake and tsunami is an essential component of tsunami warning system. This depends on number of observation systems available from well spread locations. With the existing observation network of national and international seismic stations it is possible to detect and identify any earthquake of magnitude $\geq 6.5$ anywhere in the world in less than 10-15 minutes. However, depending upon the density of the observation network, which is different in the Indian Ocean and Pacific Ocean, the earthquake detection time varies from 3 to 8 minutes. The earlier RealTime Seismic Monitoring Network (RTSMN) and the newly established Indian Seismic \& GNSS Network (ISGN) currently used for the detection of earthquakes is given in Fig. 4.

Although early detection of an earthquake is possible by using seismic data, characterization of seismic ground motion, rupture direction and its extent requires computational time to estimate its potential to generate a tsunami. The moment magnitude $\mathrm{Mw}$ is a critical indicator of tsunamigenic potential of the earthquake and it requires seismic waveform data over a longer period. Waiting for longer time period (up to 30 minutes) to gather seismic data is a limiting factor in tsunami warning. The displacement data from near-field GNSS helps overcome this limitation. The displacement data from near-field GNSS stations, if received and processed quickly, can be used for the estimation of moment magnitude much quicker than that can be achieved using the seismic wave forms.

Towards this, ESSO-INCOIS took up the project, "Indian Seismic and GNSS Network (ISGN)" to integrate the existing seismic and GNSS stations in India through VSAT connectivity and establish a permanent network of strong motion accelerometers and GNSS receivers in Andaman and Nicobar Islands. The ISGN has two Central Receiving Stations (CRSs) one at ESSO-INCOIS, Hyderabad and the other at India Meteorological Department, New Delhi and they exchange the data in real time through a high speed terrestrial connectivity. Hence, both CRSs receive data from 130 stations (100 seismic and 30 GNSS). The ISGN is designed such that it can be enhanced up to 500 stations in future. The real-time data from all seismic and GNSS stations is archived at both data centres and are made available through www.isgn.gov.in. The data from selected stations are made available for operational purposes and the data 


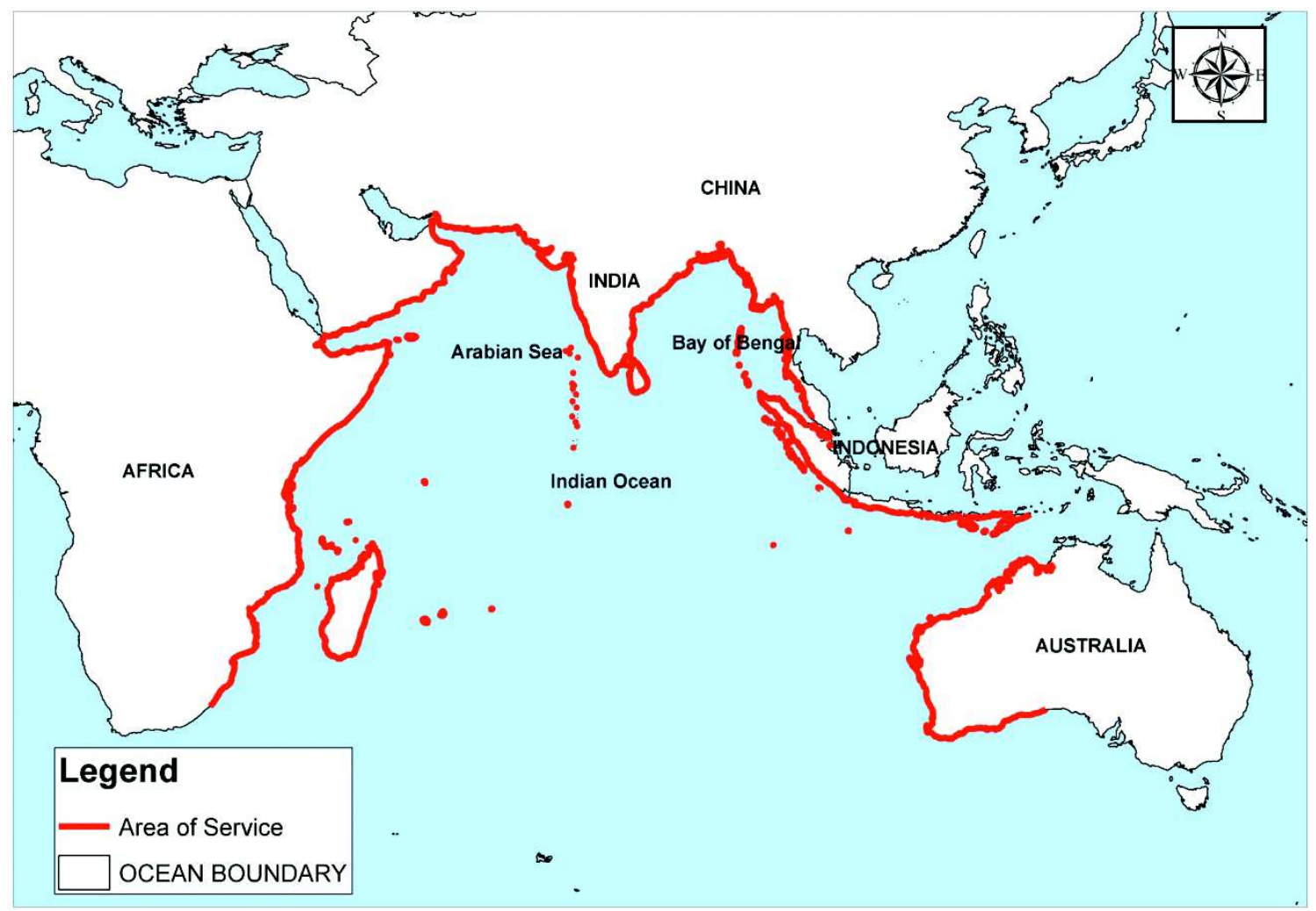

Fig. 3: ITEWC Area of Service map
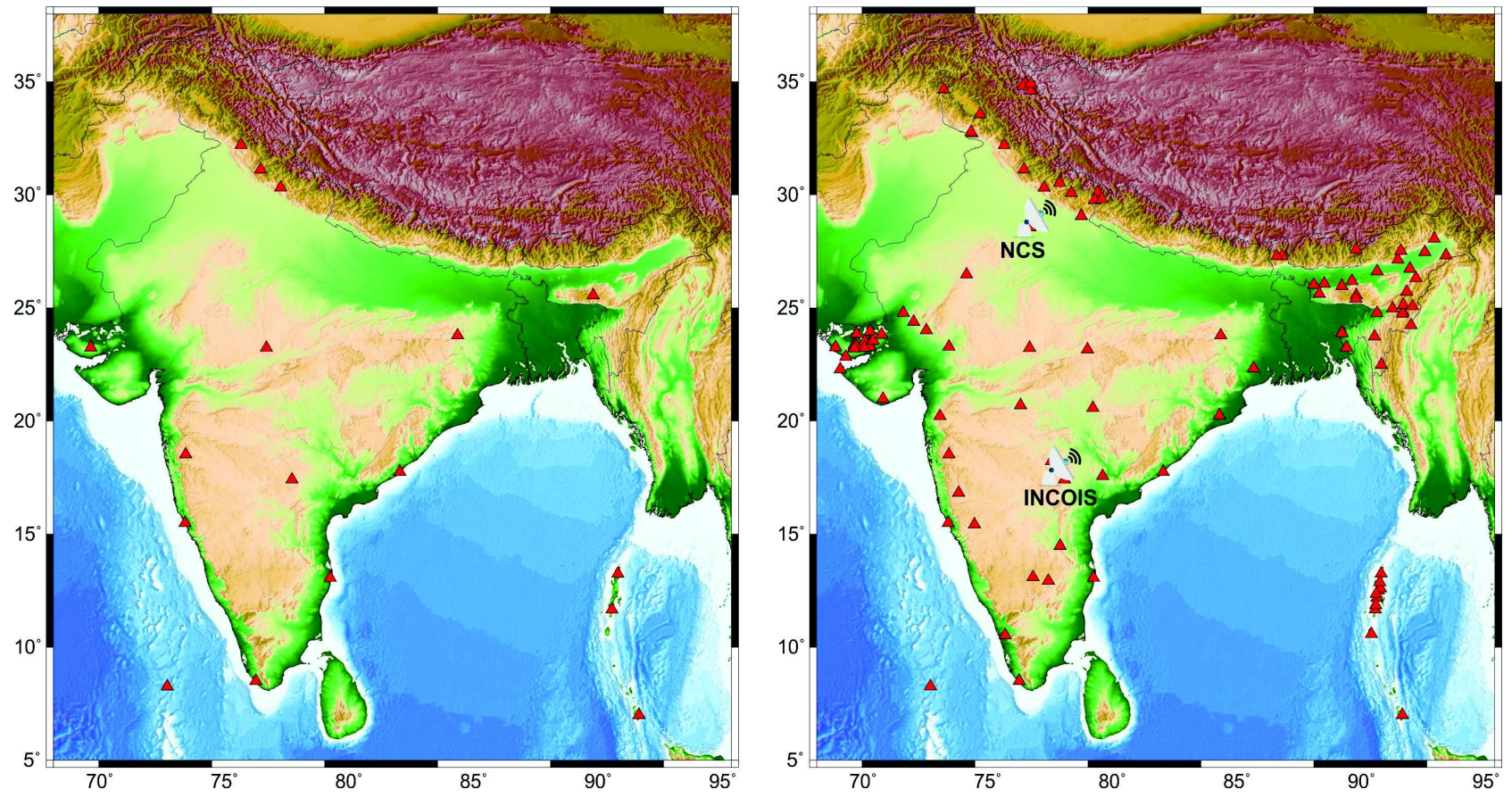

Fig. 4: National Seismic Network before and after the establishment of ISGN in 2014

from all other stations are shared with the users as per data sharing policy. The addition of new seismic stations through Indian seismic and GNSS Network has improved the performance of earthquake detection by the warning centre considerably (Fig. $5)$. 
Considering the proximity of Andaman \& Nicobar Islands to the subduction zone and little time available for tsunami warning following an earthquake that can occur in that location, ESSO-INCOIS is in the process of installing co-located Strong Motion sensors, GNSS receivers and meteorological sensors with real-time VSAT connectivity at 35 locations in Andaman \& Nicobar Islands (Fig. 6). The idea is that data from these GNSS and strong motion sensors can be used to estimate the source parameters from the displacements of near-field GNSS \& strong motion accelerometer stations much quicker than the data on seismic waves. Real-time displacement data are useful to estimate how far the stations have moved because of the earthquake and that information in turn can be used to derive the earthquake's true magnitude, called moment magnitude. This method is the best choice for rapid estimation of seismic moment tensor solutions and for determination of earthquake source in shortest possible time compared to traditional approaches using seismic data.

\section{Paleo-tsunami Studies}

The pre-computed scenario database which is used for issuing the tsunami warnings is created based on the risk estimated from historical earthquakes in the tsunamigenic sources in the Indian Ocean reported by Rastogi and Jaiswal (2006). However, to reveal any region's exhaustive threat to tsunami hazard, the historical databases alone are insufficient as they do not cover long enough periods in time. During last several years, new studies in paleo-tsunami research focusing on sedimentological record on the east and west coasts of India have turned up a treasure of information on past tsunamis in the region. Extensive work has been done in understanding the subduction zones and nature of tsunamigenic earthquakes in the Indian Ocean region in the past. Sedimentological studies along with dating of the cores along the east and west coast of India revealed the devastation caused by past tsunamis in the Indian Ocean. Researchers have dated a series of tsunami deposits

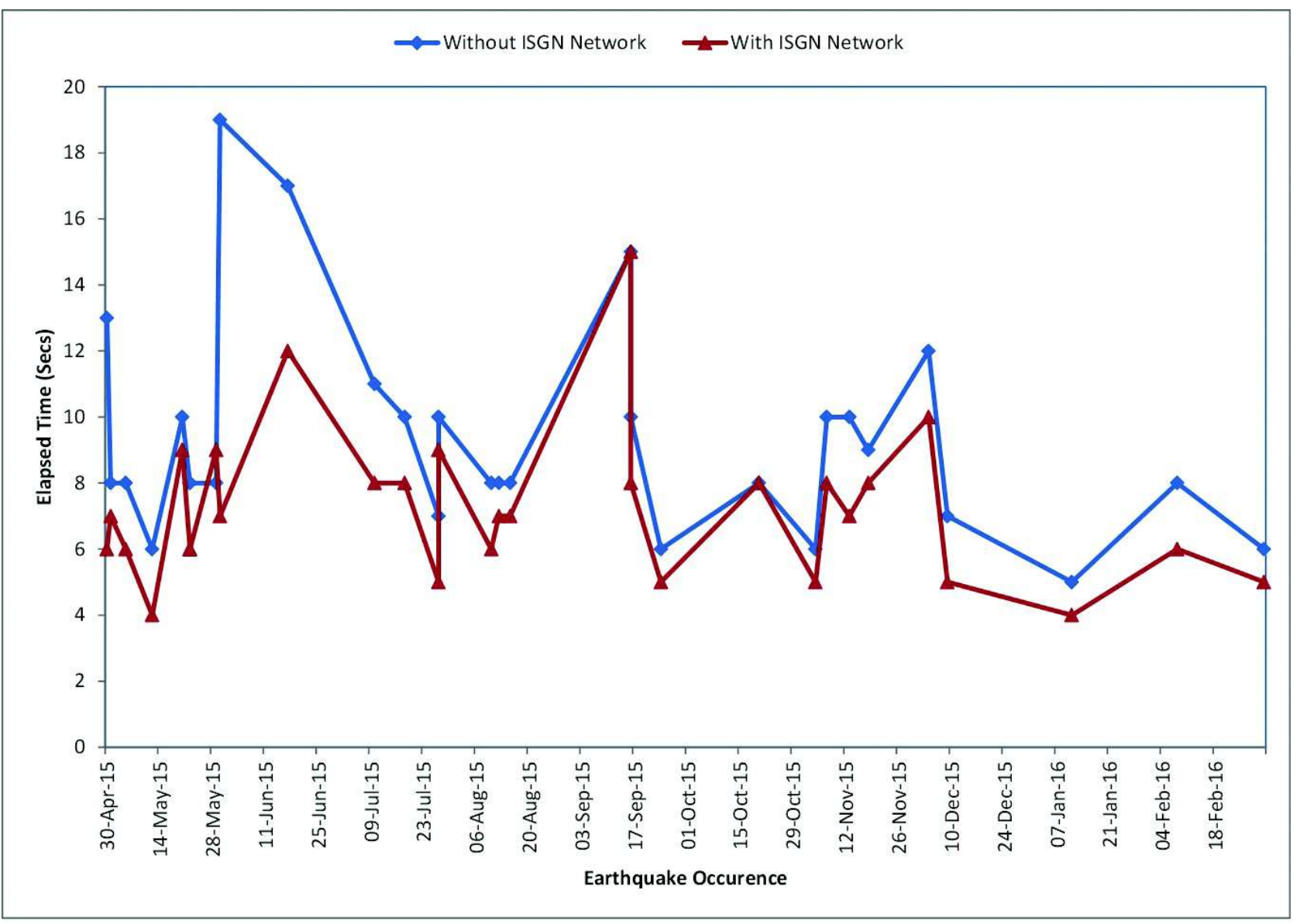

Fig. 5: Graph showing the improved detection time with and without ISGN network 


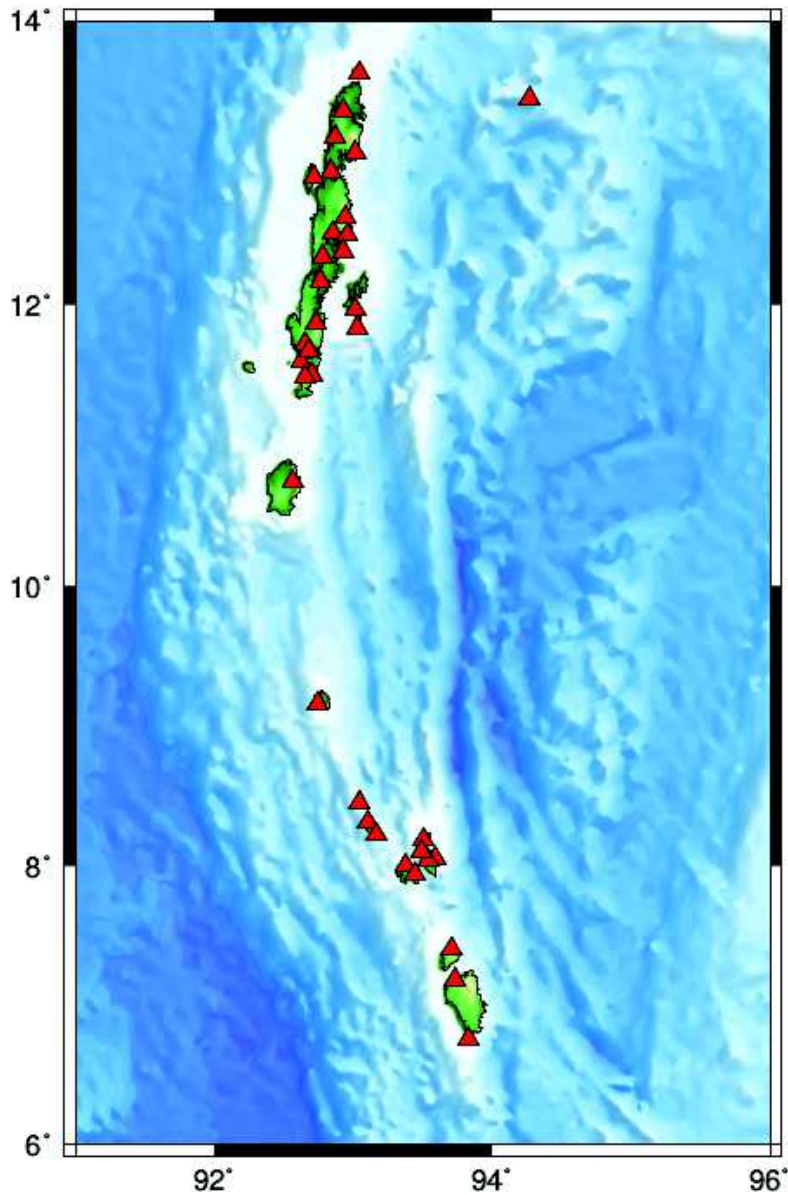

Fig. 6: GNSS \& SMA Network in Andaman \& Nicobar Islands

and determined the recurrent interval for subduction zone earthquakes and associated them with the tsunamis. Long-term data from these events can be used to establish the past record of tsunami occurrences, which is important for planning, response and mitigation of future events.

Seismological and Sedimentological study of the Makran subduction zone showed that currently, the eastern segment is more active than the western segment. Non-occurrence of large earthquakes in the western region after the 1945 earthquake indicated that this segment is currently locked and must have accumulated enough strain to generate a massive earthquake and a consequent tsunami (Rajendran et.al. 2012). Stratigraphic records obtained by Malik et al. (2015) from the west coast of South Andaman island revealed evidence of three historical earthquakes and associated transoceanic tsunamis during the past $1000 \mathrm{yrs}$ in addition to the 2004 tsunami.
Their studies suggested that the Andaman-Arakan segment is also capable of generating mega subduction zone earthquakes and transoceanic tsunamis.

Ground Penetrating Radar profiles along and across the Palshet coast (Maharashtra, India) carried out by Loveson et al (2014), revealed the presence of a paleo-beach of aprroximately $34 \mathrm{~m}$ from the present coastline (low tide line) and suggested the regression of the coast by $\sim 30-34 \mathrm{~m}$, which was due to the sand deposit ( $2.5 \mathrm{~m}$ thick) that formed a raised beach ridge in the backshore area. These raised beach sediments were deposited by an extreme event which was relatable with the cyclonic storm in 1854 . Modeling of Andaman Islands using Global Positioning System (GPS) displacements during May, 2008 - May, 2010 epoch indicated the continuation of post-seismic relaxation processes in the Andaman region (Paul et al., 2012).

Mukhopadhyay et al. (2012), had used End Point Rate (EPR) mathematical model to calculate the rate of change of shoreline and its future positions along $142 \mathrm{~km}$ coastline of Puri district, India. The model results showed that the northern part of Puri, in the vicinity of Kushabhadra estuary and Chandrabhaga beach had undergone high rates of erosion, which is also evident from the Landsat imageries from 1972-2010.

For long term forecast of future tsunamis, a probabilistic estimation can be made based on the study of past tsunamis, using historical and geological data. Paleo-tsunami works on the east and west coasts of India is helping in understanding the occurrence and recurrence of great earthquakes in the Indian Ocean since prehistoric time.

\section{Conclusion}

Refinement of Tsunami warning criteria is an ongoing process. The nation's tsunami early warning efforts have improved in several ways since 2004 and the ITEWC has been performing well and as per international standards. However, current capabilities are still not capable of providing an accurate warning or sufficient response time for a tsunami triggered due to the earthquake in near source regions. In spite of the recent advances, we still need to improve our scientific understanding of tsunamis. Accurate 
forecast of tsunami wave heights at the coast in realtime is still a challenge. The recent Japan tsunami of March 2011 has brought out important issues that have to be addressed for improving the accuracies of tsunami warning systems. Water level inversion, realtime inundation modeling, real-time estimation of focal mechanism of earthquake to show the style of faulting and incorporation of GNSS data into the warning chain are the few key issues that ITEWC has taken up on priority. All these will enable more informed decisions on evacuation, as well as to eliminate the potentially

\section{Publications}

Ch Patanjali Kumar, B Ajay Kumar, E Uma Devi, R S Mahendra, M V Sunanda, M Pradeep Kumar, J Padmanabham, S Dipankar and T Srinivasa Kumar (2015) The admissible tsunamigenic source region of 24 September 2013 landbased earthquake - application of backward ray tracing technique Current Science 108 1712-1716

Imamura F (2006) TUNAMI-N2 (Tohoku University's Numerical Analysis Model for Investigation of Near Field Tsunamis version 2) Manual

Kuwayama T (2006) Quantitative Tsunami Forecast System JICA Tsunami Seminar - Unpublished report

Loveson V J, Gujar A R, Iyer S D, Srivastava P, Tirodkar G M and Luis R A A (2014) Indications of an extreme event deposits along the west coast of India: evidences from GPR investigations Environ Earth Sciences 72 4155-4166 DOI: $10.1007 / \mathrm{s} 12665-014-3311-9$

Malik J N, Banerjee C, Khan A, Johnson F C, Shishikura M, Satake K and Singhvi A K (2015) Stratigraphic evidence for earthquakes and tsunamis on the west coast of South Andaman Island, India during the past 1000 years Tectonophysics $\mathbf{6 6 1}$ 49-65

Mukhopadhyay A, Mukherjee S, Mukherjee S, Ghosh S, Hazra S and Mitra D (2012) Automatic shoreline detection and future prediction: A case study on Puri Coast, Bay of Bengal, India, European Journal of Remote Sensing 45 201-213 doi: 10.5721/EuJRS20124519 dangerous false evacuations. The occurrence of an earthquake is unpredictable even with the latest stateof-art technologies. However, the tsunami disaster can surely be mitigated by taking adequate measures and creating awareness in the public. The communication tests and mock tsunami drill have also brought out several issues with the last mile communication of warnings, as well as the awareness and response mechanisms. The ITEWC is working with all stakeholders involved to improve upon these aspects.

Papazachos B C, Scordilis E M Panagiotopoulos, D G, Papazachos C B and Karakaisis G F (2004) Global relations between seismic fault parameters and moment magnitude of earthquakes 10th Congr Hellenic Geol Society 14-17 April 2004, Thessaloniki, pp 539-540

Paul J, Rajendran C P, Lowry A R, Andrade V and Rajendran K (2012) Andaman Postseismic Deformation Observations: Still Slipping after All These Years? BSSA 102 343-351 doi: 10.1785/0120110074

Rajendran C P, Rajendran K, Shah-Hosseini M, Beni AN, Nautiyal C M and Andrew R (2012) The hazard potential of the western segment of the Makran subduction zone, northern Arabian Sea Nat Hazards DOI: 10.1007/s11069-012-03556

Rastogi B K and Jaiswal R K (2006) A Catalogue of Historical tsunamis in Indian Ocean Science of Tsunami Hazards 25 $128-143$

T Srinivasa Kumar, Shailesh Nayak, Patanjali Kumar, R B S Yadav, Ajay Kumar, M V Sunanda, E Uma Devi and S S C Shenoi (2012) Performance of the tsunami forecast system for the Indian Ocean Current Science 102 110-114. 